Pontos de Interrogação, v. 4, n. 1, jan./jun. 2014

Revista do Programa de Pós-Graduação em Crítica Cultural Universidade do Estado da Bahia (UNEB), Campus II - Alagoinhas - BA

\title{
NARRATIVAS POÉTICAS EM VIDEOARTE DESDE AMÉRICA LATINA: UMA EX- PERIÊNCIA DE INVESTIGAÇÃo ARTÍSTICA
}

\author{
VIDEOART POETIC NARRATIVES SINCE LATIN AMÉRICA: AN ARTISTIC RE- \\ SEARCH EXPERIENCE
}

Silvana Rezende ${ }^{1}$

Resumo: Este artigo pretende compartilhar a experiência de realização, do projeto de investigação artística, Narrativas Poéticas em Videoarte desde América Latina, um projeto experimental, ocorrido principalmente, entre 2013 e 2014, contemplado no edital Setorial de Artes Visuais da Fundação Cultural do Estado da Bahia, em 2012. Expandir experiências no campo da pesquisa em arte é de grande importância, na medida em que, quanto mais a arte se aproxima do que é contemporâneo, mais narrativa da realidade se torna. Assim, cada experiência artística tem particularidades e contextualizações, que contribuem para desenvolver e atualizar estudos sobre processos artísticos contemporâneos.

Palavras-Chave: Investigação Artística. Videoarte. América Latina.

Abstract: This article presents the experience with an experimental project of art research Videoart Poetic Narratives since Latin America, occurred in 2013-2014. This work was commissioned by Department of Visual Art from Bahia's Cultural Foundation. Expand experiences in art research is very important, according as, the more the art is close to what is contemporary, more narrative of reality becomes. Thus, each experience with art has their own particularities and contextualization that contributes for development and update studies about contemporary artistic processes.

Keywords: Art Research. Videoart. Latin America.

\footnotetext{
${ }^{1}$ Universidade Federal do Oeste da Bahia (UFOB), Barreiras, Artista, Doutoranda no Programa de Pós-Graduação em Artes Visuais do Instituto de Artes da Universidade de Brasília (UnB), na linha de pesquisa em Arte e Tecnologia. Professora Assistente do Curso de Artes Visuais da UFOB. E-mail: vietkingkong@gmail.com Site: http://silvanarezende.wordpress.com
} 
Pontos de Interrogação, v. 4, n. 1, jan./jun. 2014

Revista do Programa de Pós-Graduação em Crítica Cultural

Universidade do Estado da Bahia (UNEB), Campus II - Ala-

goinhas - BA

Esta investigação artística é composta de pesquisa teórica, ações e captação de imagens, sons e impressões em 12 cidades e 5 países da América Latina, produção de videoarte, participação em mostras e festivais de arte e audiovisual, além de apresentações sobre o processo de realização do projeto, mostra de videoarte e poesia. Estas ações aconteceram entre 2013 e 2014. O projeto foi realizado em parceria com a poeta Karina Rabinovitz ${ }^{2}$, com quem desenvolvo ações artísticas desde 2005, experimentando a relação entre artes visuais e poesia.

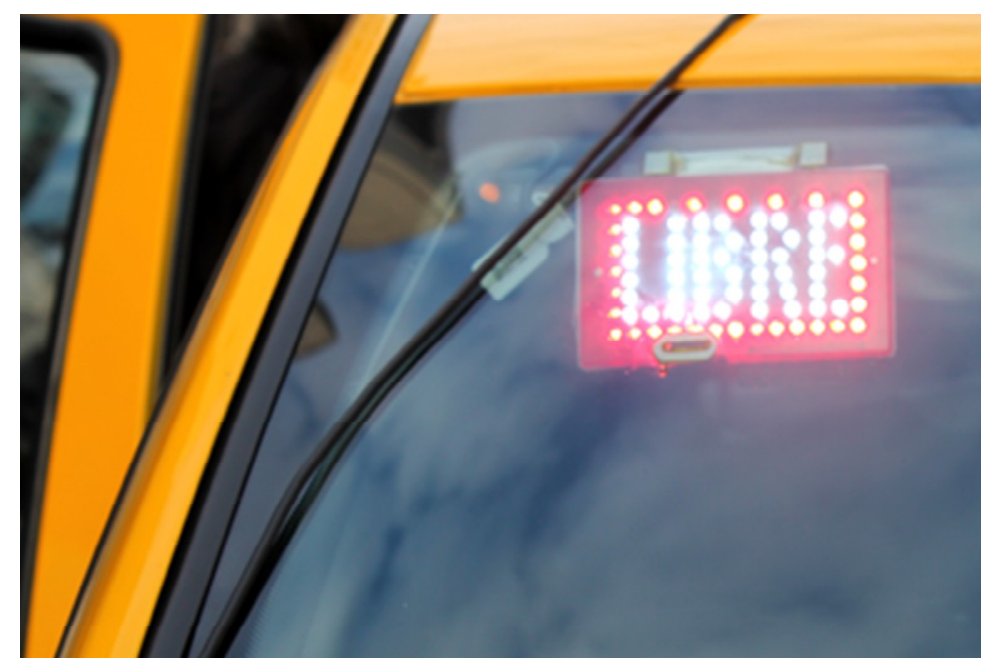

Frame da vídeo instalação “espaço urbano”, 2014.

As ações experimentais que compõem a investigação artística serão, dentro do que cabe neste artigo, detalhadas e analisadas, a partir do que foi a intenção inicial do projeto e em como ocorreu a experiência de realização, trazendo uma visão crítica, que relaciona o trabalho planejado, com o que foi realizado e seus resultados. Como se trata de uma investigação artística, e como tal, de natureza subjetiva, não se esperam resultados práticos imediatos e quantitativos. Neste projeto, consideramos como resultados iniciais alcançados: a sistematização da pesquisa teórica, a experiência vivida em campo e a análise crítica feita durante e posteriormente a esta experiência, para a criação artística com o vídeo e o compartilhamento de todo o processo - a mostra de videoarte e poesia - feitos diretamente com o público.

\footnotetext{
2 http://karinarabinovitz.blogspot.com
} 
Pontos de Interrogação, v. 4, n. 1, jan./jun. 2014

Revista do Programa de Pós-Graduação em Crítica Cultural Universidade do Estado da Bahia (UNEB), Campus II - Alagoinhas - BA

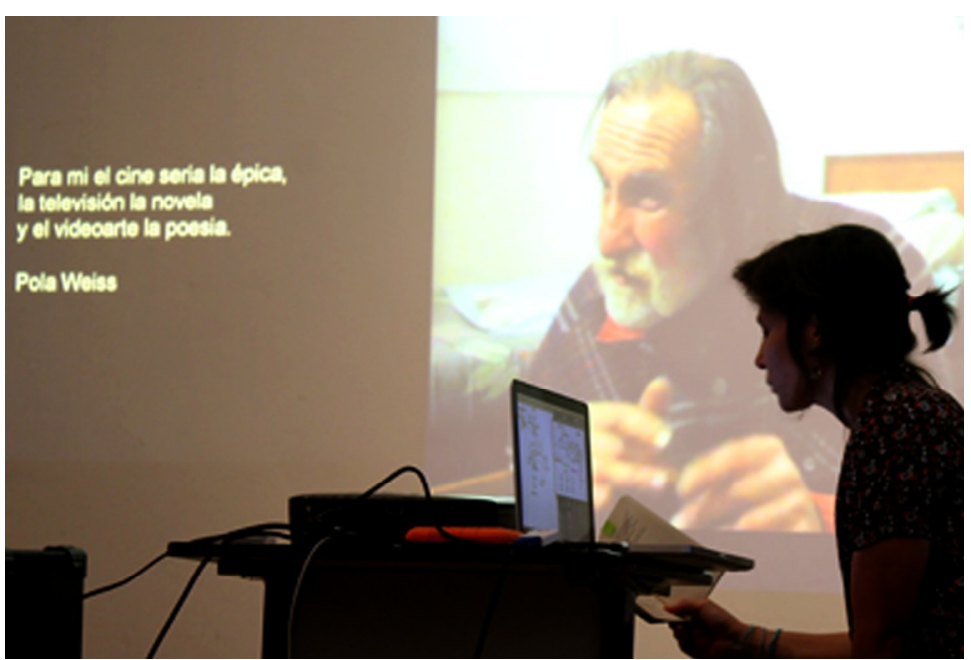

Apresentação da Investigação Artística, exibição de Videoarte e Poesia no MAC FEIRA - Museu de Arte Contemporânea de Feira de Santana-BA, 2014.

Estes resultados certamente, num segundo momento, podem ser transformados em ponto de partida para a continuação da investigação artística, quando poderá trazer outras questões e concepções. Este entendimento é importante para experimentar a sistematização de uma grande pesquisa, organizada em grupos e sub-grupos de ações, que ao longo do trabalho vãose embrenhando com o objetivo de compor um grupo maior, uma narrativa de múltiplas leituras.

A temática que guia o projeto se movimenta entre a criação artística com o vídeo e o olhar atento aos conceitos de geocultura e de espaço cultural latino-americano contemporâneo, a partir de um experiência vivida em campo. Estas reflexões, que funcionam como um conteúdo transversal para o projeto, conduziram as ações, que foram moldadas e adaptadas às condições diversas e adversas ocorridas durante todo o processo de realização do projeto.

\section{A PESQUISA TEÓRICA}

Este trabalho de pesquisa teve início a partir de um viagem a Cuba, para uma curta temporada na Escuela de Cine y TV de San Antonio de Los Baños, para uma oficina de Cinema. A escola foi fundada na década de 1980, pelo escritor Gabriel García Márquez, pelo cineasta 
Pontos de Interrogação, v. 4, n. 1, jan./jun. 2014

Revista do Programa de Pós-Graduação em Crítica Cultural

Universidade do Estado da Bahia (UNEB), Campus II - Ala-

goinhas - BA

Fernando Birri e pelo teórico Julio García Espinosa e buscava a instauração de uma escola de três mundos, para estudantes de América Latina, África e Ásia. O ambiente de imersão é proporcionado pelo método da escola de viver, comer, estudar num mesmo local, professores, alunos e funcionários, numa fazenda a 30 minutos de Havana, com o objetivo principal de pensar e fazer cinema e vídeo. A EICTV propõe uma experiência sistemática no pensar a maneira de fazer o vídeo, muito imbricada com a temática abordada, geralmente relacionada ao discurso político, social, estético e histórico. Muitos na escola achavam que o verdadeiro cinema latino-americano era assim. Sem arriscar uma resposta definitiva e focando esta experiência no relacionamento com os colegas, professores e trabalhadores da escola, vindos de diversos países, fui envolvida em questões, que causaram extremo desconforto, curiosidade e um impulso para explorar o universo poético-visual, cultural e geográfico da América Latina, para além do Brasil, lembrando que também fazemos parte deste território. Me refiro ao período de maio de 2006 e faço questão de marcar esta data, tão anterior ao início do projeto, objeto deste artigo, para pontuar que uma pesquisa ou investigação em artes pode ter seu início em época bem anterior ao início oficial dos trabalhos de investigação. Ela já começa a partir de manifestações de interesses e busca por referências e reflexões mais aprofundadas sobre criação em vídeo de um universo poético que dê conta de uma série de questões de ordem social, política, cultural e estética. Ou melhor, que pretenda criar um universo, um olhar sobre um determinado tempo de contemplação de uma vida ou de várias vidas que circulam pelas ruas e espaços por onde passamos.

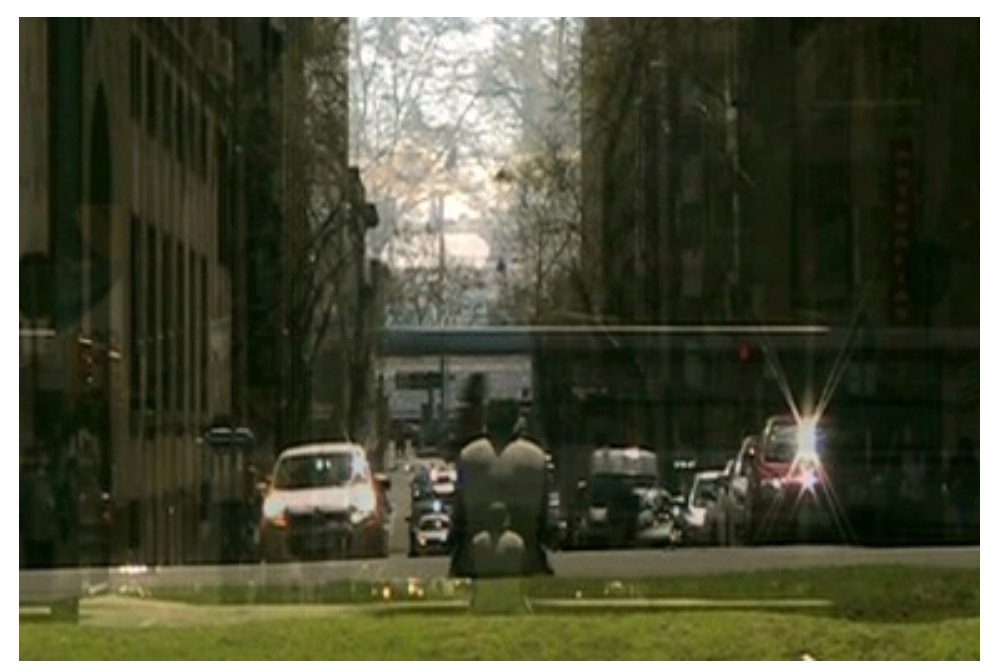

Frame da vídeo instalação “espaço urbano”, 2014. 
Pontos de Interrogação, v. 4, n. 1, jan./jun. 2014

Revista do Programa de Pós-Graduação em Crítica Cultural Universidade do Estado da Bahia (UNEB), Campus II - Alagoinhas - BA

Segundo Jean Lacri ${ }^{3}$, no livro O Meio como ponto zero, deve-se partir do meio de um assunto ou do meio de uma prática, de um saber, de uma experiência muitas vezes vivida ou do que se acredita saber melhor. Dessa maneira, combinei a minha prática artística e experiência com o vídeo, vivida desde os anos 1990 em produtoras audiovisuais, com os questionamentos que foram construídos ao longo de um período. Assim iniciei em 2012, uma pesquisa acadêmica de Mestrado no Programa Multidisciplinar de Pós-Graduação em Cultura e Sociedade, na linha de pesquisa em Cultura e Arte no IHAC/UFBA, intitulada "Videoarte e Espaço Cultural Latino-Americano: um recorte contemporâneo”, que foi defendida em Março/2014. Os teóricos estudados nesta pesquisa direcionam o olhar sobre a América Latina contemporânea, abordando questões como cultura, arte e as cidades latino-americanas. Alguns desses estudos serviram como guia teórico, um ponto de partida, para a realização das atividades propostas nesta investigação artística.

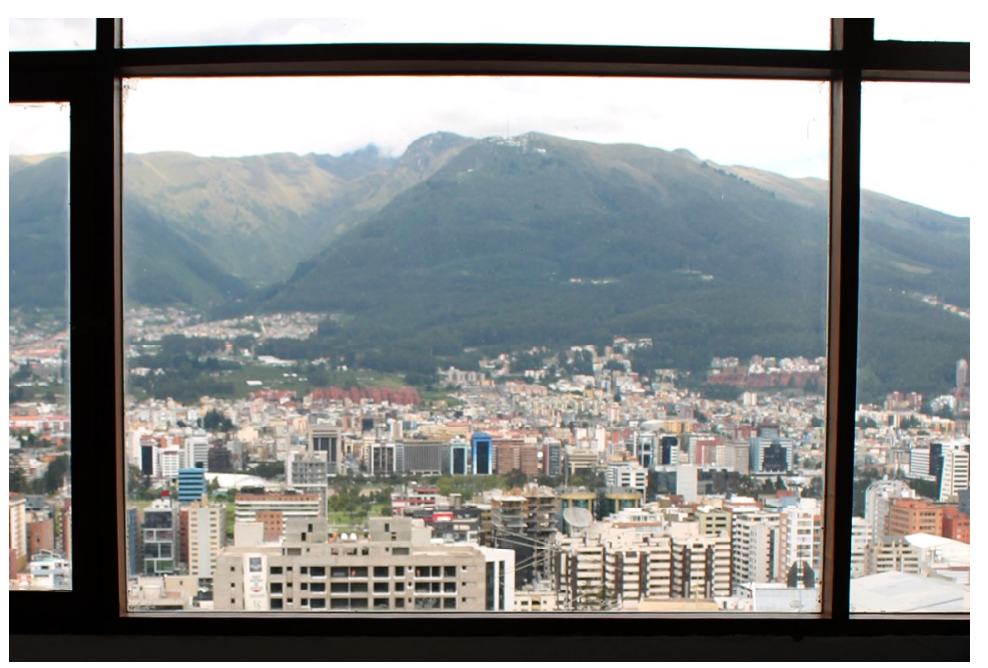

Frame da vídeo instalação “espaço urbano”, 2014.

O conceito de espaço cultural latino-americano intensifica o olhar para este território, com atenção para as diversas realidades que de alguma maneira, possuem um ponto de encontro.

\footnotetext{
${ }^{3}$ LANCRI, Jean. Colóquio sobre a Metodologia da Pesquisa em Artes Plásticas na Universidade. In: BRITES, Blanca, TESSLER, Elida (orgs.). O meio como ponto zero. Metodologia da pesquisa em Artes Plásticas. Porto Alegre: Editora da Universidade UFRGS, 2002. Pgs. 15 a 34.
} 
O espaço latino-americano, de maneira objetiva, pode ser composto por certos ritos históricos, por falta de racionalidade instrumental, pelo papel do estado e a política, pela existência de subespaços como as fronteiras e os espaços econômicos, pelas emigrações, por modelos de vida urbana e outros contextos culturais (GARRETÓN, 2008:47).

Muito antes de entendermos o espaço cultural latino-americano de que fala Garretón, o filósofo argentino Rodolfo Kusch, propôs um conceito que compõe bem esta ideia, a noção de Geocultura que promove a abertura do pensamento, uma compreensão ampliada sobre o espaço geográfico em que vivemos, onde nos organizamos e principalmente onde desenvolvemos nossa visão de mundo. Para o professor Mauricio Langón, estudioso da obra de Kusch, esses conceitos colaboram para estudos transdisciplinares, nas áreas da filosofia, sociologia, da cultura, das artes, entre outros.

El "punto de vista geocultural hace referencia a un contexto firmemente estructurado mediante la intersección de lo geográfico con lo cultural ${ }^{4}$. Fundamentalmente consiste en considerar que todo espacio geográfico - todo "habitat" - está siempre ya "recubierto" por el "pensamiento del grupo", y que éste está siempre "condicionado por el lugar". De modo que no cabe hablar de "geografía" y "cultura", sino de "unidad geocultural” (LANGÓN, 2005:1).

É como dizer que toda arte produzida num determinado espaço também está condicionada a sua realidade geocultural. Dessa maneira, considerar o espaço cultural e geográfico como elementos importantes para a realização de uma investigação artística, se torna uma ação natural. O mundo contemporâneo se organiza a partir da realidade e dos acontecimentos nas cidades. Mesmo com as distâncias cada vez mais estreitas, promovidas pelos meios de comunicação da atualidade, a realidade das grandes e pequenas cidades latino-americanas ainda carregam muitas influências de uma história de colonização e dominação econômica, e também cultural, fenômeno chamado por Milton Santos de metrópole incompleta.

O fenômeno metrópole incompleta encontra sua explicação nos dados da história internacional, da história nacional e da história regional. Os dois últimos grupos são condicionados pelo primeiro, e o terceiro pelo segundo. Há,

\footnotetext{
${ }^{4}$ Kusch, Rodolfo. Esbozo de una antropología filosófica americana. pp.14-15

${ }^{5}$ Kusch, ibid.
} 
Pontos de Interrogação, v. 4, n. 1, jan./jun. 2014

Revista do Programa de Pós-Graduação em Crítica Cultural

Universidade do Estado da Bahia (UNEB), Campus II - Ala-

goinhas - BA

pois, uma sorte de hierarquia de causas. As causas internacionais são dadas pelas condições de entrada em cena das modernizações e da industrialização do país ou da região. É decisiva a data em que ocorrem esses fenômenos (1982:69).

Associado a este fenômeno apresentado por Santos, a percepção da realidade nas cidades contemporâneas latino-americanas, esta ainda ligadas à relação entre as culturas tradicionais indígenas com a organização padronizada das cidades ocidentais. O fato de que os trabalhadores informais das ruas são, em sua maioria, indígenas ou negros, nos confirma uma herança muito presente dos tempos da colonização européia, comum nas diversas cidades visitadas por esta investigação artística, confirmando também, a dominação econômica que rege todas essas relações, sociais e culturais, uma mistura de discriminação não somente econômica, mas também de etnia. Os estudos que relacionam a realidade contemporânea das cidades latino-americanas, com os meios de comunicação, também lançam um olhar crítico para esta realidade, principalmente para conteúdo e estética da produção difundida nesses meios. São estudos que abordam o período de colonização nas Índias até os dias atuais, a fim de compreender como foram e ainda são construídos e mantidos, os imaginários visuais de determinados espaços culturais e de que maneira essas imagens se perpetuam e controlam o imaginário contemporâneo.

A partir de esta reflexiones es posible pensar el papel que cumplen los medios audiovisuales en la producción y reproducción de lo que podríamos llamar como 'tele-colonialidad', que trabaja sobre el control geopolítico de la alteridad a nivel global basado en la administración de imágenes a distancia (LEÓN, 2012:8).

A partir dessas reflexões, não se tornou mais possível pensar numa pesquisa no campo das artes, que não considerasse elementos de outros campos do conhecimento, como as questões históricas, sociais, políticas e culturais, características de um espaço geográfico e seu contexto contemporâneo. Para esta investigação, está considerada, de maneira intensa, a relação entre arte e cultura, entendendo que numa produção artística estão presentes, todos estes elementos. 


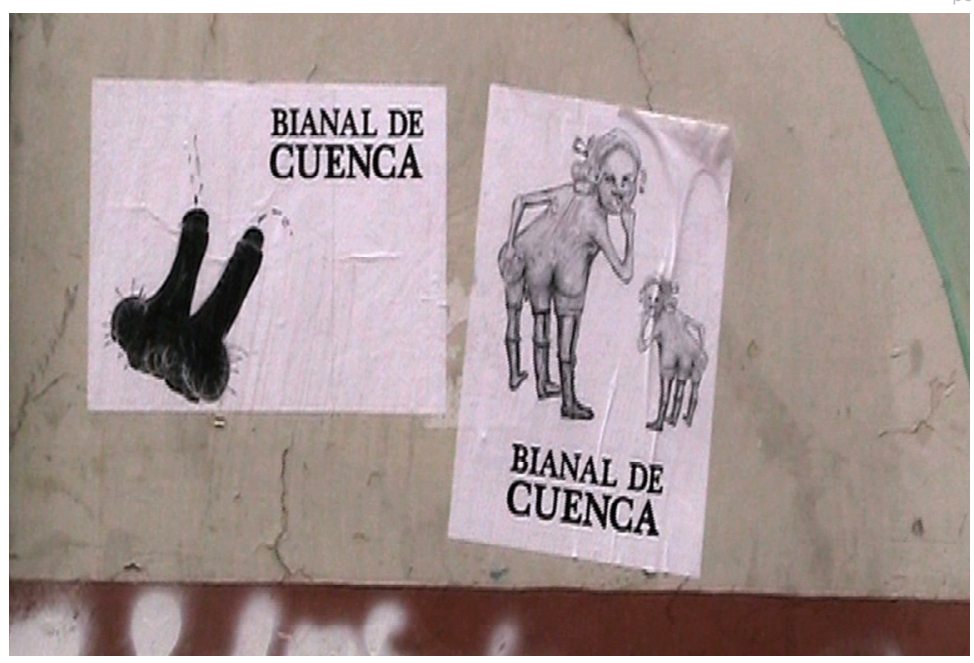

Frame da vídeo instalação “espaço urbano”, 2014.

Dentro deste universo de pensamento, entendemos que a arte e suas práticas, ainda assim, não se encerram em questões históricas, sociais, políticas e culturais. Uma vez inserido o processo de leitura e criação de um contexto, a pesquisa em artes se inclina para suas questões mais específicas, como bem aponta Teixeira Coelho ${ }^{6}$.

\begin{abstract}
“Arte é a crítica (a crítica do hábito, para começar: a crítica da cultura), a procura crítica, a especulação crítica. Em síntese, cultura é hábito; arte, liberdade” [...] "A obra de arte é muito mais pessoal (ou muito menos impessoal) do que quase qualquer outra produção da vida, e mais do que qualquer outra coisa toca de perto a alma, o desejo e a sensibilidade de quem a faz e de quem a recebe”. (2008:142-106)
\end{abstract}

Com base nessas referências teóricas propusemos uma experiência em campo, em território latino-americano. A proposta foi uma deriva, ou seja, um exercício de errância urbana, por algumas cidades no Brasil, Uruguay, Argentina, Equador e Chile.

A errância urbana é uma apologia da experiência da cidade, que pode ser praticada por qualquer um, mas que o errante pratica de forma voluntária. O errante é então aquele que busca o estado de espírito (ou melhor, de corpo) errante, que experimenta a cidade através das errâncias, que se preocupa mais com as práticas, ações e percursos, do que com representações, planificações ou projeções. [...] A questão central do errante estaria na experiência ou prática urbana ordinária, diretamente relacionada com a questão do cotidiano (JACQUES, 2008).

\footnotetext{
6 Teixeira Coelho é Curador, Professor e Teórico das Artes.
} 
Pontos de Interrogação, v. 4, n. 1, jan./jun. 2014

Revista do Programa de Pós-Graduação em Crítica Cultural Universidade do Estado da Bahia (UNEB), Campus II - Alagoinhas - BA

A intenção foi de realizar uma investigação artística que resultasse na criação de uma poesia audiovisual, de uma ação artística com um olhar sensível em direção a um cotidiano poético, um olhar de quem está do lado de dentro, o intraordinário, vendo a partir do lado de dentro.

\section{CRIAÇÃO E REALIZAÇÃO DE VIDEOARTE}

O processo de criação e realização de narrativas poéticas em videoarte aconteceu de forma experimental, fundamentados na pesquisa teórica, nos roteiros de deriva elaborados durante o projeto e na experiência artística das realizadoras. Esta experiência se fundamenta nos trabalhos já realizados pelas artistas Silvana Rezende, idealizadora, autora do projeto e videasta e Karina Rabinovitz co-autora e poeta. A dupla experimenta, desde 2005, composições entre artes visuais, videoarte e poesia.

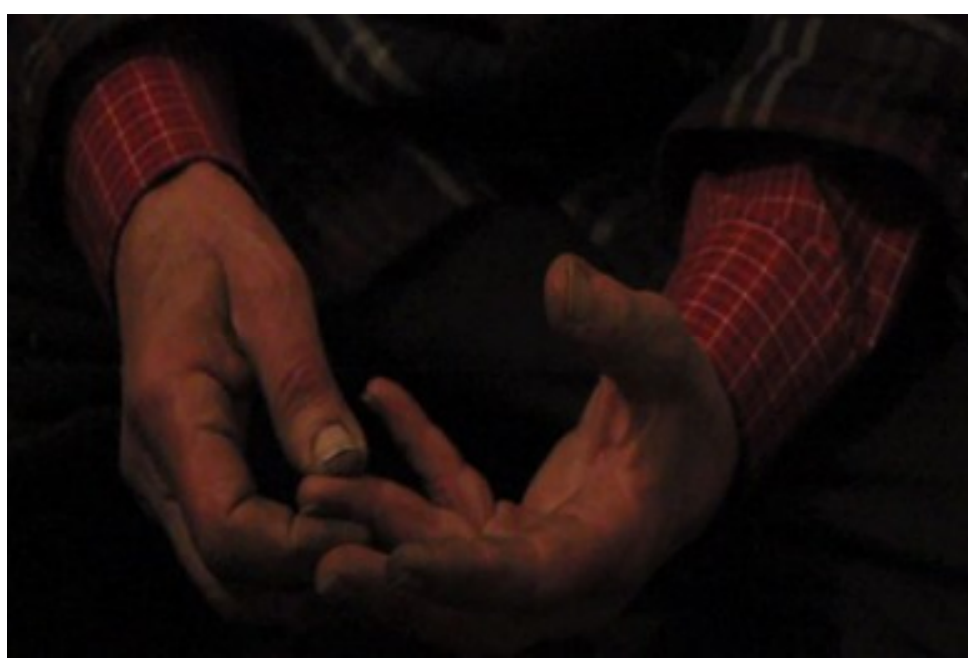

Frame da vídeo performance poética “nuño”, 2014.

Os roteiros preparados e utilizados como ponto de partida para a experiência em cada lugar, eram criados a partir das pesquisas iniciais, mas principalmente a cada dia, na tentativa de criar um fluxo de movimentos, a partir dos acontecimentos e situações em que nos colocávamos. Foram durante essas ações, de contemplação, de exploração e de repetição, que realizávamos as captações de imagens, sons e impressões. Para cada lugar, nos organizávamos de uma determinada maneira, em composição com os impulsos e as respostas que experimentávamos. As decisões que alimentavam os roteiros, envolviam também questões características 
Pontos de Interrogação, v. 4, n. 1, jan./jun. 2014

Revista do Programa de Pós-Graduação em Crítica Cultural Universidade do Estado da Bahia (UNEB), Campus II - Alagoinhas - BA

de uma realização audiovisual, que vão desde a escolha de um modo de ação a ser experimentada em determinada locação, até a definição de equipamentos, materiais, passando por desenhos de produção, contatos no local, deslocamentos possíveis, etc.

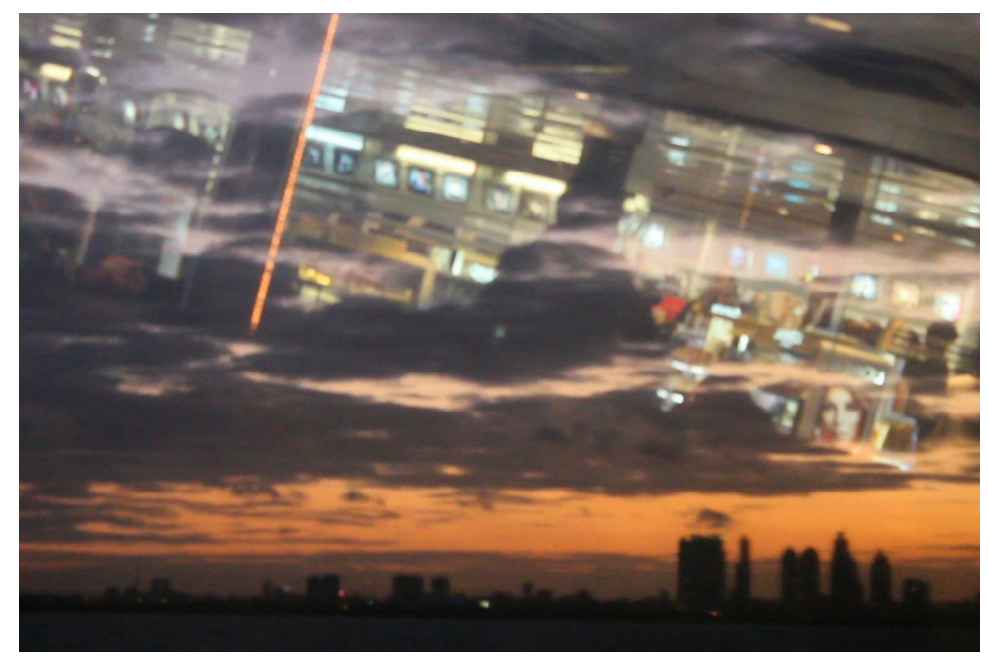

Frame da vídeo instalacão “espaço urbano”, 2014.

A realização foi dividida em partes, inicialmente com a captação livre de imagens e sons, durante o período de viagens, sempre pontuadas pelos princípios que construíram o projeto de pesquisa, associado aos impulsos e acontecimentos não programados. Foram experimentadas 12 cidades, como Salvador e Cumuruxatiba, no Brasil, Montevideo, Florida e San Jose, no Uruguay, Buenos Aires na Argentina, Quito, Guayllabamba, Cuenca e Mindo, no Equador, San Pedro do Atacama e Sierra Gorda no Chile. A justificativa para a escolha de cada cidade, se fundamenta em questões diversas, pela origem das artistas, pela contemporaneidade das cidades, pelas particularidades das pequenas cidades, pelo território, pela história, pelo impulso de conhecer com o corpo, pela necessidade da presença e outros motivos de ordem subjetiva e também prática, como custos e tempo de realização de cada deriva. A experiência em cada uma dessas cidades, compõem um grupo de imagens e sons que pretendem ser um tempo e um lugar, com histórias que se distanciam e se encontram entre si. A costura dessa realidade se estende às questões artísticas interessantes à pesquisa, como um olhar poético para o cotidiano e uma insistência em ações aparentemente já conhecidas, algo como um déjà $v u$ induzido, como se o que fosse sendo acompanhando nas imagens já tivesse sido vivenciado, como uma sensação de memória embassada, quase esquecida. 
Pontos de Interrogação, v. 4, n. 1, jan./jun. 2014

Revista do Programa de Pós-Graduação em Crítica Cultural Universidade do Estado da Bahia (UNEB), Campus II - Alagoinhas - BA

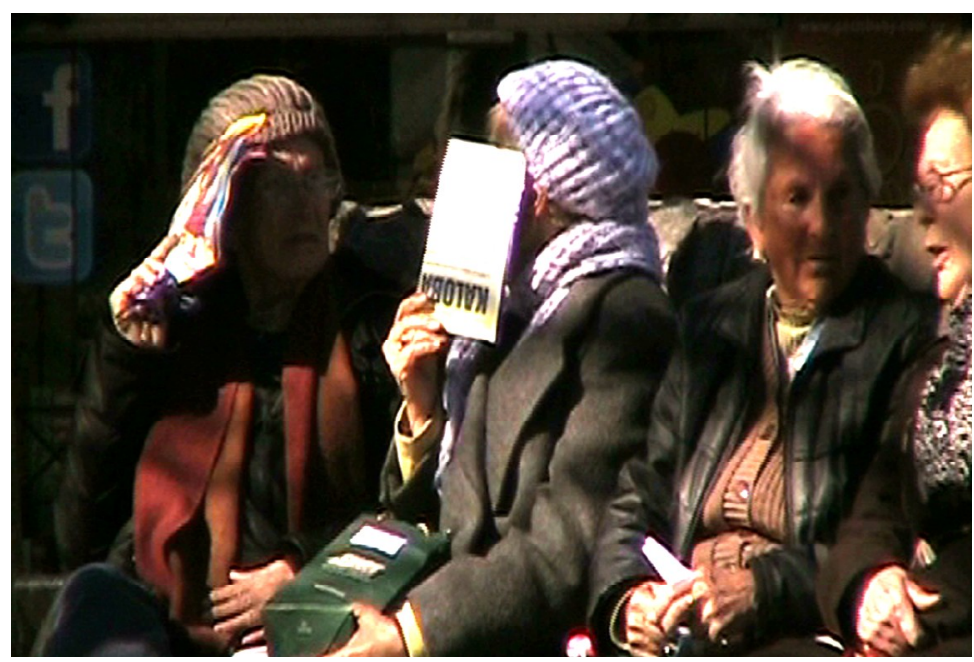

Frame do vídeo “praça, facebook, twitter”, 2014.

Após este primeiro momento de captação de imagens e sons, o segundo movimento foi de catalogação do material captado, para a construção de um banco de imagens, sons e textos. Este segundo momento apresentou um tempo de realização mais extenso do que o imaginado, já que se tornou necessária, uma análise mais detalhada do material, para a composição de um segundo roteiro, a ser utilizado na edição. Também foram necessárias montagens diversas, a fim de transformar o material captado no cotidiano, em arte. Como o próprio projeto propunha, foram finalizados vídeos de narrativas poéticas experimentais, compondo assim, um grupo de imagens diversas, que dialogam entre si, apresentando não somente um vídeo, com começo e fim, mas uma composição de vídeos, como uma orquestra audiovisual, de narrativas múltiplas.

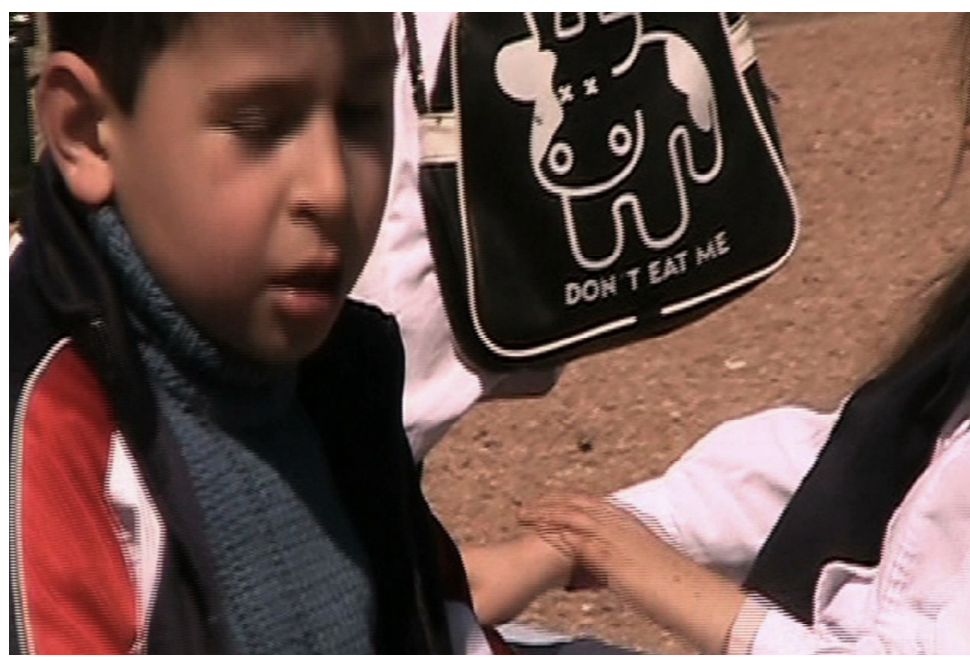

Frame da vídeo instalação “espaço urbano”, 2014. 
Pontos de Interrogação, v. 4, n. 1, jan./jun. 2014

Revista do Programa de Pós-Graduação em Crítica Cultural Universidade do Estado da Bahia (UNEB), Campus II - Alagoinhas - BA

A proposta desta realização em videoarte é experimental justamente por estar livre de formatos e categorizações que muitas vezes restringem o trabalho a classificações padronizadas, distantes e equivocadas do que a obra propõe ou mesmo o artista. Participam deste projeto a videoarte intervenção urbana, “outra dimensão”, o vídeo “ficção contemporânea I”, a vídeo instalação “espaços urbanos”, a vídeo performance poética "nuño”, e outros vídeos que, mesmo com o tempo final oficial do projeto, ainda seguem em fase de montagem e finalização. Entendemos que este projeto ainda seguirá um percurso necessário para sua maturação, um tempo que não cabe em prazos rígidos e pré-definidos. Assim, a continuação deste projeto pode promover desdobramentos ainda não conhecidos.

\section{PARTICIPAÇÃO EM MOSTRAS E FESTIVAIS}

Da mesma maneira que as categorizações, no campo do audiovisual, podem afastar o trabalho artístico do público, elas também podem contribuir para um sistema de divulgação e difusão, como as mostras e os festivais de arte. Esta investigação artística também levanta questões a respeito dessas categorizações, de que maneira elas são usadas e com qual objetivo. A mostra Videoarde ${ }^{7}$ realizada em diversos países pela pesquisadora Laura Baigorri ${ }^{8}$ é uma possibilidade importante de evento de difusão da videoarte, que traz um discurso contemporâneo e expõe uma produção voltada para questões políticas, principalmente. É um evento artístico que se concentra num recorte de produção específica, com uma curadoria bem definida e com critérios claros de recorte de uma produção. O próprio título já traz uma provocação neste sentido, convidando o público a uma experiência nada confortável e que demanda um olhar crítico, sobre questões sociais e políticas na América Latina.

La contrapartida no es generar una crónica particular que excluya a los excluidores, sino ofrecer una panorámica exhaustiva de lo que fue y lo que es el video en Latinoamérica. Así pues, este compendio selectivo de vídeo realizado sólo por latinoamericanos no trata tanto de segregación (somos diferentes), como de reivindicación: siempre hemos estado aqui (BAIGORRI, 2008:7).

\footnotetext{
${ }^{7}$ http://videoarde.net/

${ }^{8}$ Professora Titular de Vídeo na Faculdade de Belas Artes da Universidade de Barcelona. Especialista em Artes e Novos Meios.
} 
Pontos de Interrogação, v. 4, n. 1, jan./jun. 2014

Revista do Programa de Pós-Graduação em Crítica Cultural

Universidade do Estado da Bahia (UNEB), Campus II - Ala-

goinhas - BA

Estes espaços comuns de difusão, hoje multiplicados pelo mundo, podem não dar conta da produção artística em seu total, porém a proliferação de eventos artísticos, suas categorizações, exibições de obras e até premiações, também devem ser entendidos como uma necessidade do mercado em promover encontros entre os artistas, fomentar um público, organizar textos, promover as obras, e outras ações, capazes de garantir a manutenção deste sistema, entendido como sistema das artes ou ainda o mainstream.

Junto a tal mainstream existen por supuesto otras fuerzas en juego que, de diferentes modos, trabajan apuntando a delinear cartografías con base en las tensiones de la experiencia contemporánea y no en su denegación. A través de ellas se afirma el poder poético del arte: dar cuerpo a las mutaciones sensibles de una época. El volverlas aprehensibles es una acción que participa de la apertura de posibles en la existencia individual y colectiva - líneas de fuga de modos de vida que no sustentan cosa alguna a no ser la producción de capital. No será ésta precisamente la potencia política propia del arte? (ROLNIK, 2009:10).

Dentro do universo proposto por esta pesquisa de investigação artística com produção de vídeo, catalogamos uma série de festivais e mostras que acontecem na América Latina com alguma periodicidade, a fim de inscrever os vídeo finalizados. Foram encontrados inúmeros diferencias de um evento para outro, havendo a necessidade de uma busca pré-liminar, a fim de saber se as nossas obras se encaixavam naqueles critérios. A falta de categorias rígidas, pode levar os trabalhos à classificação de experimental, como acontece nos festivais tradicionais de cinema, com categorias rígidas como ficção, documental, animação e experimental. Tudo que não cabe numa ficção, num documentário, numa animação, deve se inserir na categoria experimental, ou melhor, “outros”. Antes que pareça uma crítica a esta classificação, revelo que é nesta categoria que esta investigação artística mais se organiza, por diversos motivos.

Os critérios para escolha das mostras e festivais em que seriam inscritos os vídeos do projeto, não puderam seguir nenhuma rigidez de método, já que cada mostra ou festival possui suas regras e condições de participação. Ainda assim, possui uma comissão de seleção e também de premiação, que vai eleger os melhores trabalhos e os que devem ser destacados do todo. Esta é a maneira mais aplicada a este tipo de evento. De qualquer maneira, as mostras, festivais, salões, etc, ainda se configuram como um importante meio de difusão de obras artís- 
Pontos de Interrogação, v. 4, n. 1, jan./jun. 2014

Revista do Programa de Pós-Graduação em Crítica Cultural

Universidade do Estado da Bahia (UNEB), Campus II - Ala-

goinhas - BA

ticas, tanto para os artistas já consagrados, quanto para os artistas em início de carreira, experimentais, que buscam o mercado ou apenas a exposição do seu trabalho, uma troca com o público. Os vídeos realizados durante este projeto, participaram de diversas mostras e festivais, apresentados em diversas categorias a saber:

- Segundo Prêmio Competência Oficial

Festival Latinoamericano de Vídeo Arte - FLAVIA - 2014

Centro Cultural Borges - Buenos Aires - AR

- Seleção Oficial - XIII Festival Internacional de La Imagen 2014

Muestra Monográfica de Media Art - Manizales - Colômbia

- Seleção Oficial - 4 Femcine Festival de Cine de Mujeres 2014

Cine Radicales - Santiago do Chile - Chile

- Seleção Oficial - 10 Festival Internacional de Cortometrajes Lambayeque Perú 2013

Museo Nacional de Sicán - Ferreñafe - Peru

- Seleção Oficial - Festival Cine a la Calle 2013

Museo de Arte Moderno de Barranquilla - Barranquilla - Colômbia

- Seleção Oficial - (+)AP! Festival Urbano 2012

Centro Cultural Recoleta - Buenos Aires - Argentina

- Seleção Oficial - 5a Mostra Cine BH 2011

Inhotim - Instituto de Arte Contemporânea - Minas Gerais - Brasil

Esta ação de inscrição e participação em mostras e festivais, levantou questões acerca da realização artística com o vídeo, seus critérios de classificação e categorização e também, as diversas maneiras de inserção da videoarte em espaços oficiais de circulação e difusão, na América Latina. Os vídeos produzidos nesta investigação artística participaram em Mostras de Videoarte, de Documentários, de Media Art, de Cinema de Curta Metragem e de Interven- 
Pontos de Interrogação, v. 4, n. 1, jan./jun. 2014

Revista do Programa de Pós-Graduação em Crítica Cultural Universidade do Estado da Bahia (UNEB), Campus II - Alagoinhas - BA

ção Urbana, o que chama a atenção para a característica híbrida do vídeo como prática artística e seu caráter não estático. Quanto mais se tenta classificar, delimitar e criar maneiras de sistematizar as práticas artísticas e os elementos que a compõem, mais ainda se torna necessária a promoção de reflexões sobre esta sua condição.

Em suas contaminações, o vídeo amplia seus diálogos com outras linguagens na construção de um discurso dialético. Nelas, o código videográfico não se dispersa, nem dilui nos outros códigos, mas, ao contrário, ele possui o poder de afetar e contaminar irreversivelmente a outra linguagem em diálogo. É a lógica do vídeo +, ou o vídeo que soma seus sentidos aos sentidos de outras linguagens (como no videoclip, na videodança, no videoteatro, na videoperformance, na videocarta, na videopoesia, na videoinstalação e nas intervenções midiáticas no espaço público) de tal forma que uma linguagem não pode mais ser lida dissociada da outra (MELLO, 2008:137).

Ao final das participações nestas mostras e festivais é possível perceber que o enquadramento das obras audiovisuais, se dá em diversos caminhos. O artista determina sua própria classificação? os curadores são os responsáveis em organizar e categorizar as obras? a academia e as escolas de arte criam critérios de classificação bem definidos e repassam aos estudantes, futuros artistas ou futuros profissionais do mercado das artes? É também dessa maneira que os teóricos da arte constroem o que se conhece como história da arte, recheada de leituras padrão e categorizações, que espelham uma visão de mundo? Sendo assim, se faz necessário algumas reflexões sobre que tipo de imagem estamos produzindo e de que maneira esses trabalhos chegam ao público e são lidos pelas pessoas.

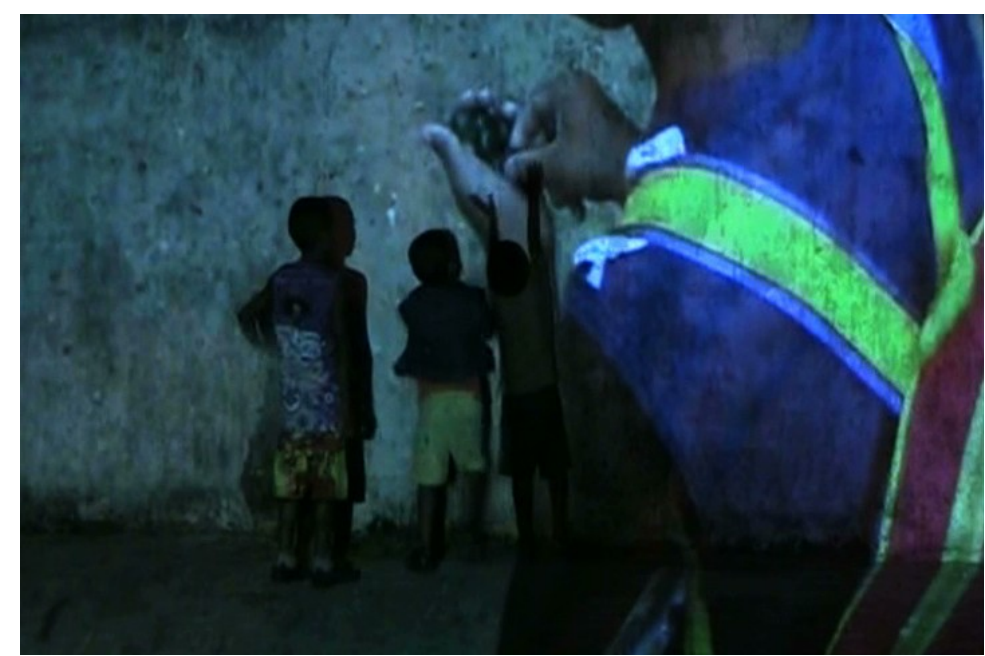

Frame do vídeo arte intervenção urbana “outra dimensão”, 5’, 2011. 
Pontos de Interrogação, v. 4, n. 1, jan./jun. 2014

Revista do Programa de Pós-Graduação em Crítica Cultural Universidade do Estado da Bahia (UNEB), Campus II - Alagoinhas - BA

Estava previsto neste projeto a presença das artistas nas mostras e festivais, que segundo a metodologia inicial, cumpriria duas funções: a de investigar o evento, os participante e as obras, e a promoção de uma deriva pela cidade em que o festival era realizado, para captação de imagens, sons e impressões, sendo este o material a ser trabalhado e finalizado para tornarse uma nova obra. Porém, dentro da realidade deste tipo de evento, não há tempo hábil para organizar uma viagem nos moldes propostos pelo projeto, muito menos se encaixou no orçamento a aquisição de passagens e hospedagens com poucos dias de antecedência, já que os festivais e mostras, muitas vezes, comunicam o resultado da seleção oficial, faltando poucos dias para acontecer o evento. Isso não inviabilizou o projeto, mas foi necessário um ajuste que rompesse o vínculo entre o país a ser experimentado com o local do festival em que houve uma seleção para participação.

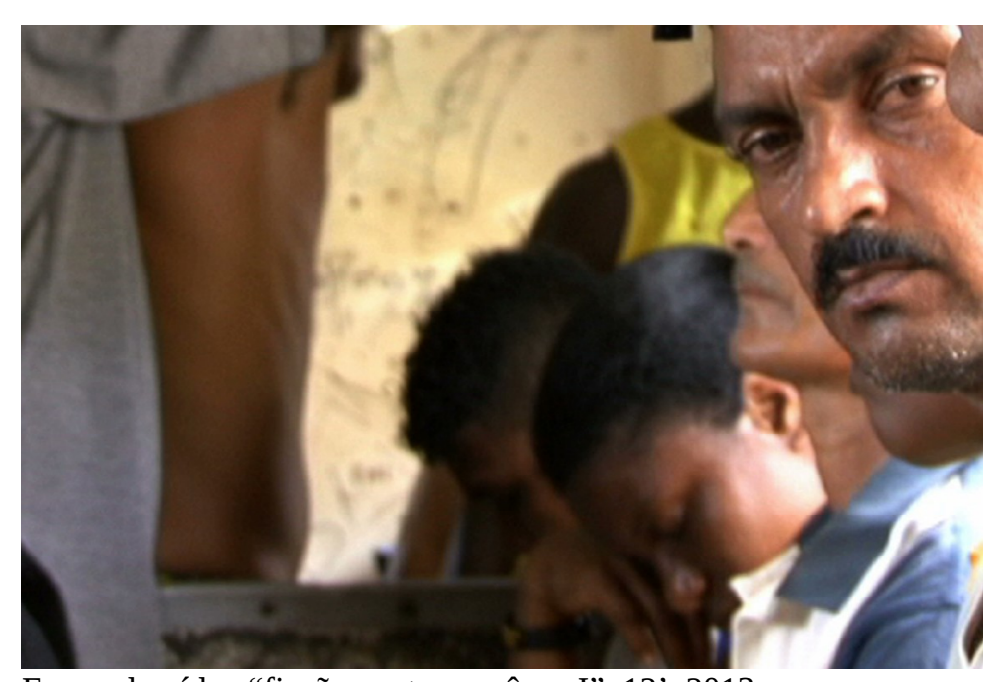

Frame do vídeo “ficção contemporânea I”, 12’, 2013.

A partir desta experiência é possível perceber que os eventos de arte promovidos por instituições públicas e também particulares, funcionam mais como um meio de difusão e acesso das obras ao público, do que como um termômetro de qualidade e capacidade criativa dos artistas e suas obras. As participações e premiações em festivais especializados em artes e suas tendências, muitas vezes alimentam a valoração das obras e determinam sua movimentação comercial. Assim, consideramos o mercado e suas regras, ao mesmo tempo em que buscamos espaços para expor os tantos trabalhos artísticos produzidos nos dias atuais, suas ideias e pontos de vista. São desde experimentações estéticas a discursos politizados, e tudo isso junto compõe uma narrativa poética da contemporaneidade. 
Pontos de Interrogação, v. 4, n. 1, jan./jun. 2014

Revista do Programa de Pós-Graduação em Crítica Cultural Universidade do Estado da Bahia (UNEB), Campus II - Alagoinhas - BA

\section{APRESENTAÇÃO DO PROCESSO DE INVESTIGAÇÃO ARTÍSTICA}

A apresentação final se tornou um espaço de troca e compartilhamento de conhecimento, experiências e percepções. Foram encontros em cinco cidades da Bahia: Salvador, Itaparica, Feira de Santana, Porto Seguro e Teixeira de Freitas, com exibição de videoarte, poesia e principalmente do processo de investigação artística, em que foram discutidas as etapas propostas pelo projeto, desde sua elaboração inicial, passando pela pesquisa teórica, produção e investigação, até a criação e realização de videoarte e participação em Festivais e Mostras de Vídeo e Arte, em países da América Latina. Foi um importante intercâmbio com o público de outras cidades, muito aberto a reflexões que relacionam as percepções sensíveis do cotidiano à criação artística. O lugar onde vivemos, a nossa ideia de mundo e como nos movimentamos entre os diversos espaços que criamos, são temáticas deste trabalho e que encontraram ecos ressoantes durante esses encontros. O público interagiu a partir de seus olhares, questionamentos e o diálogo foi enriquecedor.

As apresentações foram realizadas em formato experimental, oferecendo ao público uma narrativa audiovisual, em paralelo à apresentação oral e exibição de curtos textos. As três ações ocorrendo ao mesmo tempo, somadas à participação do público convidado a intervir a qualquer momento, se configurou numa atmosfera de envolvimento e concentração, uma imersão naquele universo, uma experiência que ao certo, será refletida com mais afinco posteriormente. O roteiro organizado para a exposição proposta, era composto de uma série de pequenos textos guias, que traziam as idéias e a metodologia da investigação artística, além dos principais itens descritivos do projeto como objetivo, justificativa, método de realização e outros, que compunham a escrita formal do projeto. 
Pontos de Interrogação, v. 4, n. 1, jan./jun. 2014

Revista do Programa de Pós-Graduação em Crítica Cultural Universidade do Estado da Bahia (UNEB), Campus II - Alagoinhas - BA

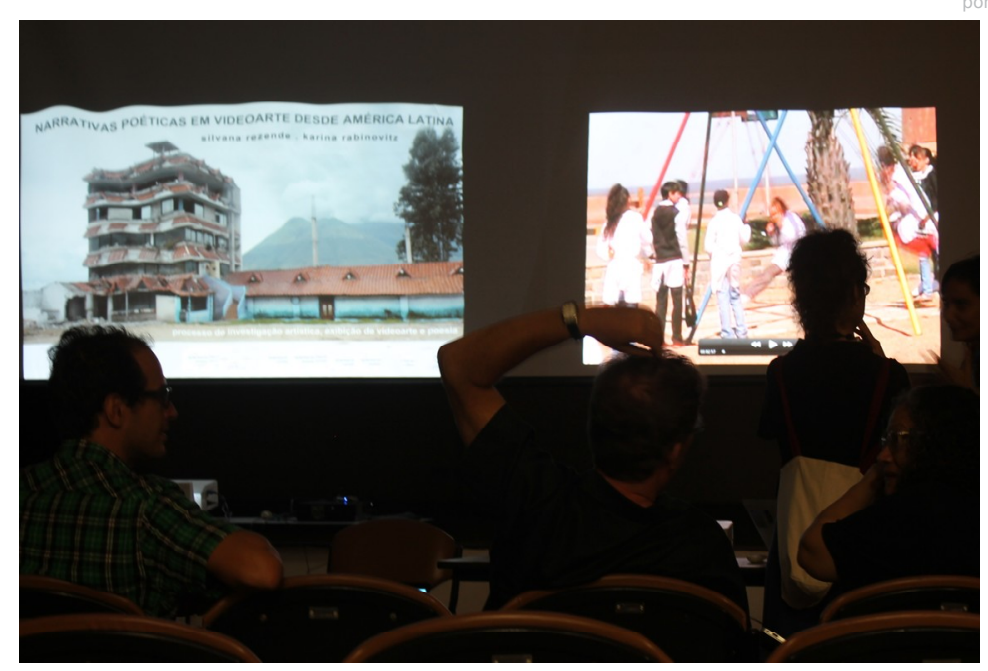

Apresentação da Investigação Artística, exibição de Videoarte e Poesia na UFSB - Universidade Federal do Sul da Bahia, em Porto Seguro, 2014.

Ao mesmo tempo em que estavam sendo expostos os processos de criação e escrita do projeto, o público acompanhava a projeção dos vídeos que compõem o projeto Narrativas Poéticas em Videoarte desde América Latina. Em seguida era exposto o resultado da pesquisa teórica e os principais conceitos considerados na investigação artística, tanto referentes a questões sociais, políticas e históricas, na América Latina, quanto a questões e estudos sobre a produção artística com o vídeo e com a poesia e as artes visuais.

Durante esta parte da apresentação, foi importante perceber como as diversas narrativas oferecidas ao público se tornaram, de fato, uma composição de narrativas, onde nenhuma delas se sobrepõe por imposição, o público é que faz sua seleção, na ordem e duração que decidir. Considerando que o grupo de vídeos que compuseram a exibição nas cinco cidades, são uma narrativa poética, podemos também dizer que são um recorte ou um retrato ou uma ficção contemporânea, captada num espaço e num tempo de encontro, de percepção do lugar pela presença. Dessa maneira, torna-se natural que ao final desta pesquisa seja feita uma apresentação diretamente com o público, abrindo a intimidade do projeto, desfolhando seus métodos e descaminhos, também contemplando as presenças e os encontros como um elemento importante para esta investigação artística.

A experiência de trocar diretamente com o público todo este processo, expandiu a exposição do trabalho realizado, já que além da exposição dos vídeos produzidos, houve também um contato direto com o público, o que não acontece em exposições tradicionais de videoarte, em que não há a presença física do artista, tampouco a discussão e reflexão sobre os processos 
Pontos de Interrogação, v. 4, n. 1, jan./jun. 2014

Revista do Programa de Pós-Graduação em Crítica Cultural Universidade do Estado da Bahia (UNEB), Campus II - Alagoinhas - BA

de realização e difusão artística. Muitas vezes quando da exposição oficial do trabalho, o artista já se encontra em uma outra pesquisa, enquanto que para o público o trabalho está nascendo. Este descompasso de tempo no encontro do público com o artista também não colabora para o estreitamento desta relação, ainda por ser mais explorada nesta pesquisa.

Por fim, acredito que o projeto Narrativas Poéticas em Videoarte desde América Latina, foi realizado com intensidade e que ainda será explorado e completado com ações e experimentos que demandam um tempo outro, que não cabe em prazos e relatórios.

O tempo oficial deste projeto foi suficiente para dar início a um outro momento da pesquisa, a uma elaboração mais aprofundada dos materiais captados, das impressões carregadas no corpo, das inquietações promovidas pelas derivas e pelas incursões nos ambientes tão familiares e ao mesmo tempo desconhecidos. O projeto terá sua continuidade, mesmo que ainda estejam sendo traçados seus novos caminhos.

\section{REFERÊNCIAS}

BAIGORRI, Laura. Vídeo en Latinoamérica: entretejiendo memorias. In: BAIGORRI, Laura (org.) Vídeo en Latinoamérica - Una historia crítica. Madrid: Brumaria AC, 2008. P.7-9

COELHO, Teixeira. A Cultura e seu Contrário: cultura, arte e política pós-2001. São Paulo: Iluminuras: Itaú Cultural, 2008. Acesso: 20 de janeiro de 2015: http://d3nv1jy4u7zmsc.cloudfront.net/wp-content/uploads/itau_pdf/001054.pdf

GARRETÓN, Manuel Antonio M. Revisitado. In: RUBIM, Linda e MIRANDA, Nadja (orgs.). Transversalidades da Cultura. Salvador: Edufba, 2008. P.45-57. Acesso: 20 de janeiro de 2015: https://repositorio.ufba.br/ri/bitstream/ufba/140/1/Transversalidades\%20da\%20Cultura.pdf

JACQUES, Paola Berenstein. Corpografias Urbanas. Vitrivius, Nº 093.97, ano 08, fev 2008. Acesso: 20 de janeiro de 2015:

http://www.vitruvius.com.br/revistas/read/arquitextos/08.093/165

LANCRI, Jean. Colóquio sobre a Metodologia da Pesquisa em Artes Plásticas na Universidade. In: BRITES, Blanca, TESSLER, Elida (orgs.). O meio como ponto zero. Metodologia da pesquisa em Artes Plásticas. Porto Alegre: Editora da Universidade UFRGS, 2002. p. 1534. 
Pontos de Interrogação, v. 4, n. 1, jan./jun. 2014

Revista do Programa de Pós-Graduação em Crítica Cultural

Universidade do Estado da Bahia (UNEB), Campus II - Ala-

goinhas - BA

LANGÓN, Maurício. Geocultura. Salas Astrain, R. (dir.): Pensamiento Critico Latinoamericano; Conceptos Fundamentales. Santiago de Chile, U. Católica Silva Henríquez, 2005, v.II

LEÓN, Christian. Imagen, Médios y Telecolonialidad: hacia una critica decolonial de los estúdios visuales. Aisthesis, No 51, Santiago, jul. 2012. p.109-123. Acesso: 20 de janeiro de 2015: http://www.scielo.cl/scielo.php?script=sci_arttext\&pid=S0718-

$71812012000100007 \& \operatorname{lng}=$ en\&nrm=iso\&tlng=en

MELLO, Christine. Extremidades do Vídeo. São Paulo: Editora Senac, 2008.

MINTER, Sarah. A vuelo de pájaro, el vídeo en México: sus inicios y su contexto. In: BAIGORRI, Laura (org.). Vídeo en Latinoamérica - Una historia crítica. Madrid: Brumaria AC, 2008. p. 159-167.

ROLNIK, Suely. Políticas de la Hibridación Cultural para evitar falsos problemas. DESBORDES N 0 - PRINCIPAL, 2009. Acesso: 01 de março de 2014: http://www.des-bordes.net/des-bordes/suely_rolnik.php

SANTOS, Milton. Ensaios sobre a Urbanização Latino-americana. São Paulo: Hucitec, 1982.

Recebido em: 29 de março de 2014.

Aceito em: 15 de abril de 2014. 